The circumstances of post-phenomenological life worlds

Derek P. McCormack

Paper accepted by

Transactions of the Institute of British Geographers

Peer reviewed but uncorrected and pre-proofing draft

Aug 2016 


\title{
The circumstances of post-phenomenological life worlds
}

\author{
Abstract \\ This paper contributes to the development of a post-phenomenological account of \\ world through a discussion of the concept of circumstance. This account is developed \\ initially through a consideration of how the concept of world figures in two important \\ strands of contemporary thinking, namely, speculative realism and theories of \\ affective life. By making connections across these approaches, the paper argues for a \\ circumstantial sense of worlds irreducible to the status of surrounds for human- \\ centred forms of life and experience. This account of worlds is post- \\ phenomenological insofar as it does not assume the already constituted subject as the \\ condition for worlds to take shape: instead, it attends to the circumstantial worlding of \\ forces excessive of the subject. At the same, via a scenographic orientation it remains \\ attentive to the affective force of life worlds, to how they are felt as a kind of \\ circumstantial palpability.
}

Key words affect circumstance post-phenomenology, scene, world 


\section{Introduction}

What remains of world as a concept for thinking about the organization, experience, and ethico-political import of spacetimes? In many domains of life, world continues to be employed to refer to the entirety of planetary existence, or to discrete aspects or sections of this existence. World in this sense is the all-enveloping "surround" in which a form of life, planetary in scale or not, is immersed. At the same time, a more limited sense of world continues to frame much work in the social sciences and the humanities, including geography. World, in this vein, is akin to a background, potentially palpable, that shapes how things show up, how they are sensed, and how they become intelligible. Drawing on various conceptual traditions, this sense of world continues to be employed in various ways, some tacit and others explicit, as part of ongoing efforts to grasp the qualities, possibilities, and politics of spacetimes (see, for instance, Thrift 2008; Adey 2014). Indeed it is difficult to avoid the injunction to elaborate more worldly modes of thinking and doing geography that mix the conceptual and empirical, that imagine different and differently inhabitable spacetimes composed of various processes and relations, myriad humans and nonhumans (Whatmore 2002; Anderson and Harrison 2010) and, going further perhaps, that work to generate the conditions in which more equitable worlds can be made and remade (Gibson-Graham 2010; Roelvink, St. Martin, and Gibson and Graham 2015).

At the same time the status of the concept has been questioned in important ways both within and beyond geography (see, for instance, Nancy 2007; Harrison 2007; Irigaray 2008; Shaw 2010; Wainwright 2010; Gaston 2013: Nancy and Barrau 2014). Perhaps most importantly, world has been problematized because it remains implicated in a human-centered, phenomenological account of spacetime. Exemplified within Geography in earlier work by humanistic geographers on the 
concept of "lifeworld" (Buttimer 1976; Seamon 1979), this is characterized by a kind of metaphysics of presence based upon the primacy of experience. More recently, however, the contours of a post-phenomenological approach to the concept of world have emerged, through developments in nonrepresentational theories (Thrift 2008), more-than-human geographies (Whatmore 2002; Clark 2006), and through engagements by geographers with varieties of new materialism (see, for example, Anderson and Wylie 2009; Roberts 2012; Shaw and Meehan 2013; Ash and Simpson 2016). However, save for some notable exceptions (Harrison 2007; Thrift 2012), the concept of world arguably remains relatively underexplored in this work: it is invoked as a concept in different ways as the horizon against which other problems (life, body, subject, nature, etc.,) are posed but does not itself often become the focus of critical attention. This tendency is not specific to geography, of course. To take but one example: in his 'plea for earthly' sciences, Bruno Latour $(2007,6)$ asks: “If the world is not made of either nature or society or any combination thereof, what is it made of?" In short, world remains as a kind of concept of last resort to which to refer when the conditions of everything else are up for grabs. And in some ways its importance would seem to becoming greater. As the philosopher Jean Luc-Nancy and Aurelien Barrau have recently argued, world "is entering into a movement of indefinite expansion, both on a 'cosmic' scale and in our methods of knowing and acting on it and within it", becoming, in the process "the crucial point where all of the aspects and stakes of sense' in general" are "tied together" $(2015,2,1)$.

Against this backdrop, in this paper I foreground the concept of world as a contribution to the elaboration of a post-phenomenological geography (Lea 2008; Simpson 2009; Ash and Simpson, 2016). My point of departure is the claim, articulated in stronger versions of the post-phenomenological materialism upon which 
this geography draws, that world is no longer a useful concept for thinking spacetimes. Notably, the philosopher Timothy Morton (2007 2013) has argued that the concept of world is now both outdated and unhelpful, remaining too humancentred for the task of grasping the massively distributed phenomena that are realities. In this paper, I use Morton's argument as a point of departure, or as a kind of limit for thinking with and against the concept of world. However, rather than dismissing the concept like Morton, I argue that it remains important for thinking the affective life of post-phenomenological spacetimes. In developing this argument I draw upon the work of thinkers of affective life including Kathleen Stewart (2010 2014) who offers a scenographic account of the affective life of worlds. Building upon this, I argue that worlds should be understood as circumstantial spacetimes irreducible to surrounds for human-centred forms of life and experience. Following Michel Serres (2008) I propose circumstance as a way of naming the extrusion of the impersonal forces excessive of a life into the worldly textures and trajectories of that life. This account of circumstantial worlds is post-phenomenological insofar as it is not centred on the human experience of life worlds. At the same time, a circumstantial approach to worlds remains attentive to the affective force of worlds, to how their "pinch" is felt in the stances of bodies and forms of life.

The paper is organized as follows. I first review briefly how world has figured in geographical thinking, before turning to the question of a post-phenomenological account of world, drawing upon the arguments of thinkers including Morton (2013) and Levi Bryant (2014). I then consider the value of the concept of circumstance as way of thinking about the becoming palpable of post-phenomenological worlds, before showing how this overlaps with a scenographic approach to worlds found in 
the work of Kathleen Stewart (2010). A short conclusion then explores some of the wider implications of this argument.

\section{Geography's worlds}

The concept of world is central to how the scope and nature of the discipline of geography has been framed. ${ }^{1}$ Writing in the late 1950s, Richard Hartshorne gave the following answer to the question of why the field of geography should exist in the first place. For Hartshorne, "the answer, surely, is that this minute part of the universe, including the rays of light and heat that enter it from heavenly bodies or from the interior of the earth, is in fact our universe, the world in which we live and which we can directly experience" $(1960,44)$. Geography, according to Hartshorne, is therefore best understood as the "discipline that seeks to describe and interpret the variable character from place to place of the earth as the world of man [sic]" (1960, 47, original emphasis).

Hardly unique perhaps, but this claim serves as a useful point of departure for thinking through the geographical framing of the question of world as a shorthand for the entire empirical scope of geography insofar as this refers to the sphere of human concerns. World is therefore both expansive, and potentially colonizing, insofar as it refers to a realm defined by the interests, reach and transformational activity of human life. Epistemologically, in this framing, world holds together two of the key problems of geographical knowledge: it both facilitates a particular mode of distanced abstraction - the world as the entire sphere of human concern grasped objectively and a sense of the "direct experience" of this sphere of concern. This tension is not specific to Geography, of course. In his recent partial genealogy of contemporary philosophical engagements with world, Sean Gaston (2013b) asks if it is possible to dispense with the ontological, epistemological and ethico-political assumptions of the 
concept as support for a privileged vantage point while also holding onto and affirming world as concept for thinking-with and within. As Gaston notes, one of the tensions that runs through the work of thinkers such as Derrida is between the "difficult imperative to be truly and authentically in the world" and the search "for the most reliable vantage point above and beyond the world as a whole" $(2013, \mathrm{x})$. This tension - between immersion and distance -is central to how world figures as a concept for geographical thinking. World remains something in which things and thinking are immersed: at the same time as it can be grasped via a move through which the immediacy of immersion is temporarily suspended. In short, the allure of world as a concept for thinking spacetimes is that it functions simultaneously as foreground and background for thinking: it is both something to be grasped and the condition for grasping.

The influence of the imperative to take some distance from world in order to map its dynamics is not difficult to detect, particularly in attempts to devise indices of economic, cultural, and political interconnectedness. This is exemplified, for instance, in world-systems analysis, anticipated in the work of Fernand Braudel (1996) and articulated most forcefully by Immanuel Wallerstein (2012). Work on the concept of 'world-cities' extended aspects of this analysis by attempting to account for nodes of influence in the organization and articulation of the financial, political, and cultural flows that hold worlds together (see, for instance Knox and Taylor 1995). Conversely, an emphasis on the direct experience of world can be traced through geographical engagements with the idea of life world, associated with phenomenologically inspired strands of humanistic geography (see also Entrikin 1976). Notably, Anne Buttimer defined life world as the "culturally defined spatiotemporal setting or horizon of everyday life" (1976, 277). World, for Buttimer, is a lived, palpable horizon of 
meaningful experience, and a phenomenologically-inspired approach to life world allows it to "reveal itself in its own terms" rather than relying upon language (1976, 277). Understood in this light, the adjective worldly designates an orientation towards thinking and life that privileges the mortal, the finite, and the fleshy as they are expressed in the rhythms of embodiment, rhythms which are "a prototype of the relationship between places and space, home and range in the human experience of world" $(1976,285)$. Drawing upon Buttimer, and also arguing from a phenomenological perspective, David Seamon (1979) similarly explored the textures and choreographies of the life worlds in which each individual is always "housed [...] and whose specifics we can change but whose surrounds in some form we can in no way avoid" $(1979,15)$. Such attention to the lived experience of life worlds offered an important corrective to particular kinds of geographical abstraction (although not to abstraction per se): it foregrounded that which tended to be backgrounded through a phenomenology that questioned the "radically the taken-for-grantedness of lifeworld" $(1979,21)$

This phenomenology of the life world was subject to various critiques, by now familiar. Not least of these was frustration with its uncritical and a-political approach, and lack of attention to the differentiated nature of lived experience (see Rose 1993). This critique of the concept of life world has been elaborated, although not always explicitly, as part of the process of developing a post-phenomenological account of worlds through different theoretical and empirical projects. Amongst the most important of these are non-representational theories (Anderson and Harrison 2010; Thrift 2007). On one level, the emphasis in humanistic geography on the pre-, or more-than-linguistic quality of life worlds experienced through the rhythms of embodiment seems to anticipate aspects of nonrepresentational theories. However, 
while such theories foreground the affective and experiential dimensions of worlds, they also try to avoid the explicit humanism of earlier accounts, problematizing the metaphysics of presence that underpins phenomenological accounts of experience by revealing how this metaphysics is haunted by absence (Rose 2006; Wylie 2009). Here experience is no longer the reference point for accounts of worlds but a condition of possibility for conceptual and empirical experiment (McCormack 2013). At the same time, such accounts attend to life worlds as fabricated arrangements of affects, practices, and objects around and against which the problems and promise of life becomes actualisable to different ends (Thrift 2011; Adey 2014). Making explicit how practices and technologies of world-making, by no means limited to the purview of the human, allow certain kinds of experience to become sense-able and valuable remains critical here (Thrift 2012).

Paralleling nonrepresentational theories, geographers have developed accounts of what Sarah Whatmore has called "more-than-human worlds" (2002). In such work there is a refusal of "any vantage point that purports to take in the world at a glance" $(2002,7)$ and a determination to diagram the affective relations through which worlds come to matter for diverse agencies. These arguments draw on strands of thinking that displace the authority and agency of the human (Latour 2007), and upon efforts to attend to corporeal sensibilities that disclose different technologies of world-building and worldly dwelling (Ingold 2011). They pose questions about whether world as a concept helps us understand the environmental surrounds of other forms of life, including, for instance, animals, and how it connects or complicates related terms like territory (see Buchanan 2008; Lorimer 2012).

The ongoing elaboration of these trajectories of thinking has contributed to the emergence of what James Ash and Paul Simpson (2016) call "post-phenomenological 
geographies". As Ash and Simpson are careful to note, these geographies do not so much dismiss the insights of phenomenology but complicate and develop them in important ways by refiguring a number of issues: for Ash and Simpson these include body, (inter)subjectivity, objects, and the social. As this suggest, there are various avenues along which a post-phenomenological geography might be explored further, and in ways that extend and complicate parallel discussions of concepts such as assemblage in this journal (see Muller and Schurr 2016). While noting these directions, I limit my concerns here to considering more closely the question of world. In doing so I also note that world remains part of the vocabulary employed by Ash and Simpson in their discussion of the post-phenomenological. Even if it does not provide one of the key terms around which their argument about a postphenomenological geography turns, Ash and Simpson conclude their discussion with the claim that post-phenomenology is about exploring the "excessive world that lies outside of the human-environment correlate but which is central to shaping human capacities, relations and experiences" $(2016,63)$.

\section{The ends of phenomenological worlds}

I want to pivot my discussion, at least initially, around a rejection rather than a reaffirmation of this excessive world. This rejection is articulated by one of the touchstones for the arguments of Ash and Simpson - the philosopher Timothy Morton (2007 2013) - whose writing is part of a wider, if differentiated set of speculative philosophical engagements with objects, realism, and materiality that is being taken up by geographers (e.g. Ash 2013, Shaw and Meehan 2013).

For Morton one of the key implications of a post-phenomenological speculative realism is the end of world as a viable concept. Engaging with Morton's claim here is important precisely because it crystallizes what might be at stake if we 
were to stop using the concept of world, while also forcing us to examine how different senses of world emerge and are sustained across various traditions of thinking. For Morton, dispensing with the concept of world is a necessary precondition for thinking the real spatiotemporality of things as part of the ecological condition and crisis of the ongoing present. This questioning of world in response to a crisis is not new of course (see Nancy 1997). As Paul Harrison $(2007,433)$ has written, the critique of the concept of world by Emmanuel Levinas must be seen in light of the "blasted social and moral landscapes of Europe during and immediately after the Second World War". At the present juncture, however, Morton's targeting of the concept serves to crystallize some of its chief difficulties. For Morton these are threefold. First, world provides a container in which to place everything else and, in doing so, offloads the work of explaining hyper-objects - entities that are massively distributed in time and space - onto a thoroughly objectified entity. To invoke world is to engage in the "objectification" of things like capitalism and climate change and to remain in thrall to mere caricatures of these entities $(2013,100)$. Second, world provides a "fragile aesthetic effect" $(2013,99)$ that prevents us from moving beyond human-centred accounts of reality. World is little more than phenomenological "mood-lighting", a comforting aesthetic smudge clouding the post-phenomenological apprehension of complex material entities, allowing us to hold onto the affectively imbued promise of a shared surround. Third, by backgrounding this surround, we tend to foreground processes or phenomenon that are simply the localized and limited expression of the qualities of non-worldly hyper-objects.

Morton's broader argument is provocative and in many ways persuasive. He offers a rich set of concepts for thinking about entities that exceed the conceptual and perceptual frames of the social sciences and humanities. But his argument about 
world needs qualification. Consider one of the examples he uses in his argument against world: the contrast between climate and weather. For Morton, grasping climate change as a hyper-object means modifying our understanding of weather: weather becomes a "flimsy, superficial appearance", a "mere local representation of some much larger phenomenon that is strictly invisible" $(2013,104)$. As he puts it, weather has

A false immediacy, an ontic pseudo-reality that can't stand up against the looming presence of an invisible yet far more real global climate. Weather, that handy backdrop for human lifeworlds, has ceased to exist, and along with it, the cozy concept of lifeworld itself. Lifeworld was just a story we were telling ourselves on the inside of a vast, massively distributed hyper-object called climate $(2013,103)$.

We can push back against this claim and its implications in a number of ways. First, and critically, the distinction Morton makes between weather and climate turns around the fact that the latter is more 'real' than the former: weather is only a superficial expression of a real entity or hyper-object called climate change. If we follow Morton's logic, a cloud as an entity is less real than the atmospheric conditions from which it is generated, and for two reasons: it is 'merely' the localized expression of these conditions, and it is smaller. Morton's analysis turns around questions of scale and moreover, because the entities with which he is concerned are massively distributed in relation to the perspective of the human, the ghost of human perspectivalism he finds so problematic remains at the center of his analysis. It is precisely the scalar sublime of Morton's argument that precludes him from considering the possibility of modifying concepts of life world, for instance, through what Tim Ingold has called "weatherworlds" (2010), in ways that recognize their composition from human and non-human entities. The allure of the hyper-scales of 
hyper-objects mean Morton has little to say about the cautious affirmation of the affective-material force of the local or limited expression of atmospheric phenomenon such as gusts of wind, rainstorms, or lightning strikes. A second point also arises from Morton's framing of weather as an epiphenomenon of climate. If we remember that for Morton "no entity at all has a world" $(2013,108)$ then it is difficult to imagine how we might develop or mobilise a vocabulary for thinking spacetimes in any other ways than in terms of entities or objects. It would make little sense, for instance, to speak of atmospheres in an affective and/or meteorological sense, unless they are 'mere' local expressions of much more distributed entities.

A third point about Morton's understanding of world concerns his association of world with a kind of scenographic affective aesthetics that occludes or clouds thought. As he writes, "the idea of world depends on all kinds of mood lighting and mood music, aesthetic effects that by definition contain a kernel of sheer ridiculous meaninglessness" $(2013,105)$. When framed in terms of an appeal to worlds as shared horizons of meaning, these comments have acerbic bite. It is just a little too easy, however, to cast as dupes those who see the conceptual or ethico-political value in this possibility: as if they were audience members who could not see past the scenographic illusions presented to them. Morton can claim that "world is an aesthetic construct that depends on things like underground oil and gas pipes" $(2013,106)$, but forgets that it is perfectly possible to hold in view both infrastructures and the aesthetic affects they generate at the same time. Equally, there may well be some value to mood lighting as part of experiments with the consciously framed "as-ifness" of worlds.

A fourth point concerns the ethics that follows on from this. For Morton, “even if world were a valid concept altogether, it shouldn't be used as the basis for 
ethics" $(2013,107)$ because it is both selective and exclusionary. Worlds draw ethical and political boundaries that always run the risk of ignoring connections across those boundaries, a point that could be made about any conception of spacetime. Morton affirms instead an ethics and politics based upon "intimacy" $(2013,108)$, on the intensity of interconnectedness with other entities. Thus, "without a world, there are simply a number of unique beings (farmers, dogs, irises, pencils, LEDs, and so on) to whom I owe an obligation through the simple fact that existence is coexistence" $(2013,125)$. Only when we dispel the "charm of world" will we be able to truly appreciate "ecological co-existence" $(2013,126)$. The irony here is that Morton cannot dispense with some sense of a connective environmental surround. He calls this the "mesh": a world-like concept in the place of world. The mesh is an "emergent property of the things that coexist, and not the other way around" $(2013,130)$. But it is not entirely clear why we cannot make a similar claim about "world": world could easily be understood as "an emergent property of the things that coexist", and in a similar vein to how the concept of place can be considered in terms of a set of relations of simultaneity (Massey 2005). And it could be easily understood in terms of what Nancy and Barrau call an "uncoordinated simultaneity": a kind of "continuous creation where what is constantly rekindled and renewed is the very possibility of the world" $(2015,4952)$. In other words, there is nothing about Morton's argument that precludes us thinking of worlds as part of the elaboration of a post-phenomenological geography.

However, a less acidic approach to world can be gleaned from other sources within the orbit of speculative realism. In particular, we can take some orientation here from the work of Levi Bryant (2014) - whose writing, as Ash and Simpson (2016) also note, contributes to the elaboration of a post-phenomenological 
geography, and who also draws inspiration from the relational approach to spacetime articulated by Doreen Massey (2005). Bryant, like Morton, foregrounds the role of entities and agencies beyond the human in order to produce a post-phenomenological realism. However, where Morton dispenses with the category of world, Bryant reworks it. Indeed, the central aim of Bryant's project, which he calls "ontocartography", is the "analysis of worlds" $(2014,111)$. This involves mapping the "relations between machines or networks of machines composing a world" (2014, 111). ${ }^{2}$ Critiquing Deleuze, Bryant claims that world is not the same as the means by which it shows up, or is encountered, through whatever logic of sense. Nor can world be apprehended, as it were, in its totality, but can only be inferred as an "ontologically flat" network of anarchic relations between machines (2014, 115-116). World remains implicit, shadowy, a "loosely coupled assemblage of machines interacting with one another through the mediation of other machines in an ecology" $(2014,114)$.

For Bryant, worlds do not pre-exist the relations of which they are composed, even if they "preside over the local manifestations of machines" $(2014,118)$ in the ways that Morton's hyper-objects do. Worlds are not globe-like containers for discrete entities, but more like turbulent atmospheres without "fixed or defined boundaries or elements", akin to "a gaseous cloud in Brownian motion or fireflies flickering to each other” $(2014,122)$. Echoing Morton, Bryant suggests worlds are like continuously shifting 'meshes' rather than fixed things that cohere through a form of 'gravity'. Gravity is the degree to which "one machine bends the space-time movement and becoming of another entity" $(2014,188)$. While it is not really clear what this term brings by way of explanatory power, it allows Bryant to conceive of onto-cartography as a matter of mapping the worlds of relations rather than thinking about their essence. Thus, onto-cartography explores "the gravitational relations 
between machines arising from the manner in which they mediate one another so as to determine why assemblages take on the patterned organization they possess" (2014, 197). In the process, Bryant outlines the possibility of a post-phenomenological account that de-centres worlds of human experience without dismissing the concept of as the afterglow of that experience.

\section{Circumstantial worlds}

Another important point can be drawn from Bryant's work. This is attention to the circumstantial qualities of post-phenomenological worlds: to how the capacities of bodies, machines, or entities to affect and be affected are shaped by the pull, or by what Bryant might call the 'gravity' of a non-coincident, non-unified arrangement of simultaneity, and indeed to how this arrangement is felt in forms of life as the possibility of a world. In fact, the concept of circumstance is central to Bryant's work. As he notes, "one of the central aims of onto-cartography is to draw attention to the way in which circumstances can structure the agential possibilities open to machines as a result of gravity they exercise in forming paths along which the machine moves, [and] locally manifests itself' $(2014,222)$.

Circumstances are not only conditions lying outside and impinging upon human life but are ongoing, loosely consistent structurings of influence on the capacities of diverse agencies to affect and be affected by other agencies. To foreground the shaping force of circumstance is, of course, nothing new. Thomas Aquinas, in Summa Theologica, also writes at length of circumstance as something that bears upon the human act while also remaining beyond its essence. For Aquinas, circumstance is described as "something outside the substance of the act, and yet in a way touching it." ${ }^{3}$ Circumstance also provides the conceptual pivot around which more recent understandings of contingency - in life, thinking, and politics - become 
possible. For Marx, famously, "Men [sic] make their own history, but they do not make it just as they please; they do not make it under circumstances chosen by themselves, but under circumstances directly encountered, given, and transmitted from the past' $(2000,329)$.

Michel Serres, perhaps more than any other philosopher, deploys the circumstantial as a concept for thinking spacetimes. For a thinker whose work is often characterized by flow, turbulence, and mobility, circumstance is a concept that allows Serres to gather a mingled given: to give palpable shape to that which is stabilized in relation to the contingent fringe of fluctuations and variations from which it emerges (see also Anderson and Wylie, 2009 Cresswell and Martin 2012). Circumstance, he writes, "is a splendid description of the productive work of the local and its temporary movement, space and time; plus the periphery which encloses it and inside which an equilibrium is at last established and holds sway; plus the set of fluctuations surrounding the open windows in the membrane or skin or frontier or wall or enclosure" (2008, 293). For Serres, what is interesting about lives, bodies, storms, subjects, etc., is how they take on a kind of metastability: that is, their very stability, limited and localized, is an ongoing composition of all the forces and fluctuations, internal and external, that fringe their form $(2008,304)$. This sense of circumstance is certainly not circumscribed by the orbit of the human, or by the sphere of human action: it reaches out to what Morton calls hyper-objects. And yet Serres is not afraid to foreground the palpable sense of the circumstantial. His sense of circumstances may be hyper-objective but it does not, like Morton, reject affective palpability as mere phenomenological mood lighting.

Critically, for Serres, circumstance is not a spatial container or surround. It is a spatiotemporal unformed envelope whose shape is open. The time or temps of 
circumstances is therefore meteorological: it is a cloud of conditions that can precipitate as a shape of change. World in this sense is a circumstantial metastability, or what following Serres, we might call a circumstability: a spacetime always being tensed by the pressure of incalculable variations in the cloud of variations from which it emerges. In this sense, the circumstantial is the particular configuration of elements and forces transversal to scale, from the force of the elements to the molecular economies of a body, that provide the conditional constraints within which a sense of something happening emerges. What this means then is that worlds do not subsist fully formed in the background ready to be foregrounded when the circumstances are right. Rather, worlds take place as the circumstantial shaping of non-coincident forces such that they become conditions of palpability.

\section{Scenes of affective worlds}

Why this emphasis on palpability? In part, because I want to avoid the charge that the upshot of this discussion of circumstantial worlds is a rehearsal of a by now familiarif still important - story of assemblages as worlds in the making (see, for instance, Anderson and MacFarlane 2011; Muller and Schurr 2016). And I want to do this by exploring the affective dimensions of worlds, by which I mean the ways in which the pre-personal relations and perturbations between objects become palpable in bodies. There are good reasons for remaining attentive to the affective palpability of postphenomenological worlds. First, even if the human or the corporeal no longer inevitably provides their frame of analysis, theories of affect can still offer purchase on the kinds of worlds, subjectivities and capacities that emerge through massively distributed processes and assemblages (Anderson 2014; Clough et al. 2014). Second, foregrounding the affective can make accounts of worlds more attentive to the force of things (Bennett 2010) both in relation to how this force shows up and is sensed by 
humans, and in relation to how things affect and are affected by other things through a "gravitational pull" that is not shaped by human intervention. Third, theories of affect complicate the notion of intimacy proffered by Morton as the basis for a post-worldly ecological ethics. Certainly, they require us to think about how intimacy involves the complex articulation of affective relations simultaneously public and private, and invite us to consider whether or not this term helps us understand relations between non-human things (see, for instance, Berlant 2000). Fourth, attending to the affective provides a way of holding on to the importance and value of the "as-if" qualities of worlds as limited and localized expressions of more general affective "infrastructural commons" (Berlant, 2016). Foregrounding affect reminds us that these localized expressions are no less real for generating a limited palpability as the emergent outcome of a mesh of machines, or of the pipes and cables of real and virtual infrastructures (Thrift 2008).

Where then to turn for help in thinking about the affective dimensions of circumstantial worlds? One source, perhaps unlikely, is the empiricism of David Hume. As Gilles Deleuze writes, 'the notion 'circumstance' appears constantly in Hume's philosophy. It is at the centre of history and it makes possible a science of the particular" (1991, 103). Equally importantly as far as Deleuze is concerned, in Hume's work circumstance "always refers to affectivity" (1991, 103). As Deleuze continues, affective circumstances "are precisely the variables that define our passions and interests. Understood in this way, a set of circumstances always individuates a subject since it represents a state of its passions and needs, an allocation of its interests, a distribution of its beliefs and exhilarations" (1991, 103). In Hume, therefore, Deleuze locates the beginning of an affective empiricism: it is within the given of affective circumstances that the practical and processual rather than 
representational constitution of subjectivity takes place. A cartography of the circumstances that provide for the possibility of difference in perception, in thought, and in feeling, is a map of the affective forces through which subjectivity is individuated.

There remains plenty of scope, therefore, for thinking about the affective dimensions of post-phenomenological worlds without resorting either to a kind of subject-centred humanism or a form of realism that rejects any sense in which forces in excess of human bodies are felt in those bodies. We might think of this as the question of how localized folds in spacetime become palpable (see Ash 2015). Or we might think of it as akin to what anthropologist Kathleen Stewart calls an attunement to "worlding". For Stewart, worlding is about the matter of how "events, relations, and impacts accumulate as the capacities to affect and to be affected" $(2010,339)$. Stewart understands this process through the concept of the refrain, borrowed, in turn, from Deleuze and Guattari (1988), to refer to the scoring or ongoing compositional holding together of worlds in ways that are always open to the force of internal and external variation. The work of critique, in this sense, is about becoming "attuned to the worlding of the refrain", to "what takes form, hits the senses, shimmers" (2010, 339). As she continues, this might be "a condition, a pacing, a scene of absorption, a dream, a being abandoned by the world, a serial immersion in some little world you never knew was there until you got cancer, a dog, a child, a hankering.... and then the next thing - another little world is suddenly there and possible" (2010,339). Stewart reminds us, then, that the concept of world, or of worlding, can still do work by providing a way of holding on to the affective force of a form of gathering.

This means, in turn, that thinking about and with the circumstantial becoming of worlds requires the cultivation of particular modes of attunement. This is where 
Stewart's work is also important, as a marvelous exemplar of what it means to enact a form of thought that tries to catch the becoming palpable of worlds in scenes of life: a form of thought in which the labour of doing theory is much more compositional than analytical. This is also a form of speculative realism, or more accurately a compositional realism, one that 'has to stay nimble in the effort to keep up with the distributed agencies of what's throwing together and falling apart" (2015: 20). It is not simply an attentiveness tensed by the possibility that somehow worlds lurk in the background, ready to appear at some point. It is about learning to sense and become responsive to how the circumstantial becomes palpable as an immanent process of worlding from within. Attending to the circumstantial is also, therefore, a mode of acting out of and into the circumstantial: it is an attunement to the immanent process of worlding, a responsive to the ongoing fluctuations of the circumstantial as that which touches the act or event without ever being essential to its substance.

Stewart's work reminds us of the power of writing as a circumstantial mode of worldly prehension through experiments in form. It reminds us that writing and thinking are always already circumstantial, already "inscribed already in a complex network involving the language in which we write, with all the sedimentations that language brings with it, and all the differential and semi-independent histories that intersect at this point, on this occasion, this circumstance in which I now myself reading and writing, singularly constituted by everything that tends to compromise my singularity just as soon as it makes it possible" (Bennington 2000, 1). Writing has no monopoly in this respect, however. A circumstantial mode of attunement might also be a practice or performance that takes shape as a kind of ongoing responsiveness to being tensed by worlds. To this end, in Being and Circumstance, the artist Robert Irwin outlines a phenomenal aesthetics conditioned by the circumstantial. As he 
writes "what our perception presents us with (at every moment) is an infinitely complex dynamic, whole envelope of the world and our being in it” $(1985,10)$. A phenomenal art, for Irwin, consists in actively responding to the circumstances of being as becoming, possibilities he discerns in sculptural practice that gives shape to the play of becoming between being and circumstance, the latter of which:

Encompasses all of the conditions, qualities, and consequences making up the real context of your being in the world. There is embedded in any set of circumstances and your being in them the dynamic of a past and future, what was, how it came to be, what it is, and what it may come to be $(1985,28)$.

This kind of circumstantial aesthetics is post-phenomenological insofar as it takes the becoming of being as an ongoing process of forces immanent to the subject or the organized form of bodies. Performance offers other possibilities. For instance, in Product of Circumstance (1999) the French choreographer Xavier Le Roy presents a performance lecture that takes circumstance into account through the mode of acting that constitutes the performance. The lecture combines biographical details about Le Roy's background in cellular biology and a series of stories of his involvement in choreography. Chronological, the lecture nevertheless opens itself to the circumstantial matters of bodies and affects and their ongoing recomposition through variations issuing forth as examples. As Petra Sabisch notes, these examples are "irreducible to a material proof of evidence supporting the argument of the lecture. They are examples, but at the same time they exceed their singularity and orchestrate, in concert with the other demonstrated parts, a significantly different "lecture" that also renders the speech act readable as performance of typical rhetorical gestures and as an arepresentational usage of literary genre" $(2011,56)$. Examples, in this context, are both circumstantial insofar as they touch upon a mode of acting, while remaining 
tangential to its essence. Through examples, circumstances cross-contaminate in a way that also refuses any separation between those circumstances and their performance.

The question of performance reminds us also of one of the targets of Morton's critique of world as a form of scenographic mood lighting. For Morton, remember, world provides an unrealistic backgrounding and foregrounding that borders on the ridiculous, transforming our grasp of complex hyper-objects into little more than badly produced melodrama. Equally, world gives the scenes of this melodrama a certain aesthetic glow. But it is precisely the capacity of scenes to provide occasions for backgrounding and foregrounding that shapes Stewart's approach, something she shares with other key thinkers of contemporary affective life including Lauren Berlant (2011) and Elizabeth Povinelli (2011). Stewart writes worlds as circumstantial scenes. The staged quality of these scenes does not necessarily get in the way of grasping the reality of things, but provides a technique of glimpsing how worlds show up as the emergent outcome of arrangements of things, devices, props, etc. A stage or a set is a machine for producing the aesthetic scenographic affects of a world and, what is more, those who witness the production of these affects often know it: they are not dupes. And because they live these scenes they must go along with their as-if quality, at least most of the time. It is rather long-sighted to dismiss the work of making sense of these worlds as mere efforts to grasp a sense of the local expression of a larger object. Indeed, as both Berlant and Stewart make clear, the scene is a useful, if also partial way of understanding how the singular becomes general in the commingling of the ordinary without adding up to anything like an account of a discrete entity. For Berlant, this involves "gathering up scenes of affective adjustment to material that mediates the ongoing present across the recent, the now, and the next" $(2011,15)$. 
And yet, even if these modes of writing and performing provide ways of working with the circumstantial as the post-phenomenological condition for phenomenological experience, they may well not go far enough in allowing us grasp the circumstantial processuality of our distributed hyper-objective and hypersubjective realities. This is amplified, perhaps, by the development of new forms of non-human technologies including, most obviously, big data, algorithms, and sensing devices of different kinds. In a recent commentary on some of the implications of "big data" Nigel Thrift has written that its proliferation "will change our notion of circumstance. Things won't have to have a true now. The immediate will be able to be multiple. Round the corner will no longer mean as much" $(2012,1265)$. Similarly, Patricia Clough and her colleagues have written of the emergence of a data-logical present that is post-affective and post-phenomenological because it consists in the ongoing iteration of technologies of prehensive sensing that work below thresholds of human sensing (2014; see also Hansen 2014; Kinsley 2014; Leszczynski 2015). To take these developments into account may mean that the modes of writing and acting outlined above remain too tethered to the affective circumstances of subjects, and not attentive enough to circumstantial worlds that precipitate from the aggregates and clouds of data in which bodies move. It may well be that these clouds are growing in extent, duration, complexity, and that the primary circumstantial mode of acting through which the present takes shape is algorithmic and machinic: it may be about the capacity to sense localized expressions of hyper-objects, or the capacity to prehend the coming into form of new associations that happen far too quickly for subjective awareness. And it may well be that a form of aesthetics that can grasp this on its own technical terms will be the primary and privileged mode of circumstantial awareness. As Clough et al, following Hansen (2014) argue, this is the kind of 
aesthetics exemplified, for instance, in the work of Jordan Crandall, which tries to draw out the calculative ambience of worlds. ${ }^{4}$

But this does not mean that the modes of writing or thinking or performing outlined earlier will somehow become redundant. They will remain valuable as modes of acting that respond to the ongoing fluctuations of the circumstantial as that which shapes the process of worlding without being its essence. Their value, in part at least, is that they slow down the circumstantial, gathering it in tensed scenes of life, scenes that are inevitably partial without necessarily assuming the primacy of the phenomenological experience of the human. In this context, world-writing or worldperforming remains important precisely because it provides opportune occasions for taking up and being taken up by the "force that opens up another world, a force that is immanent to the existing world" (Cheah 2008, 35).

\section{Conclusion}

Taking Timothy Morton's as a point of departure for thinking about what happens if we dismiss or dispense with the concept of world, in this paper I have tried to outline the terms of a more affirmative account of world, in which it is not simply a background in which entities are immersed or from which they emerge, nor mere mood lighting for a purely phenomenological stance. Drawing in particular upon elements of the work of Levi Bryant, Michel Serres, and Kathleen Stewart, my argument has been that worlds take shape as circumstantial gatherings of noncoincident simultaneity that can be sensed. Clearly, I am not claiming that world is deployed in the same way across all the thinkers and traditions of thinking outlined above. World is not a metaphysical conceptual object whose essence is to be withdrawn from all other others. Rather, it is deployed circumstantially as a way to grasp how relations become circumstantially palpable. But what does link the 
thinking of Bryant, Serres and Stewart is a commitment to a form of speculative realism, in which 'reals' (to use Stewart's, 2015 phrase) can be conceived in terms of circumstantial worlds. Equally, there is more work to be done than can be undertaken in this paper to differentiate this sense of world from engagements by geographers with concepts such as site, assemblage, and place: as a stop-gap, I would observe that the engagement with world is important because even in analyses of these other concepts, world tends to be invoked as a generalized background or backdrop for a discussion of something else (see, for example, Marston, Jones and Woodward, 2005) My claim here is that the circumstances of worlds are all the forces in excess of an actual entity or occasion (to use Whitehead's 1967 terms) that become foregrounded insofar as they become sensed and palpable to that entity and occasion. To make this claim is not to reduce or confine the concept of world to the human: instead, given the range of devices and technologies through which sensing takes place, it is to understand worlding as the process by which different infrastructures of sensing make the force of the circumstantial palpable. Worlding, then, does not presuppose the existence of spacetimes prior to the non-coincident processuality of the circumstantial (see Merriman 2012). Nor however does it envisage a way of thinking 'without' the sense of spacetime associated with world. Worlding is the way in which circumstances generate enough pressure to be felt in the tensed arrangements of bodies of one kind or another.

A number of points follow on from this post-phenomenological understanding of circumstantial life worlds. First, there is always a certain cost in holding onto the concept of world, no less than any other spatiotemporal concept. As Gaston notes, efforts to be done with the concept of world and to reinvent it in ways that separate it from some sense of perspective are equally problematic. Neither can escape the 
tension between immersion and transcendence captured by the term, nor can they escape the ghostly spectre of the human as the centre of a form of perspectivalism. As Gaston puts it, "there are worlds and they are always less than a world" (2013, 164).

The second point is that a circumstantial view of world complicates the tension between immersion and abstraction that shapes debates about the concept (McCormack 2012). To foreground world is often assumed to be about emphasizing presence, about foregrounding experience: certainly, this is one of the critiques leveled at the way in which the concept of life world has been deployed in phenomenologically oriented accounts of experience. But to world, as a verb, is itself to abstract in the sense of drawing something out: that is, the process of worlding is a circumstantial drawing out of a patterned palpability. It is, as Nancy and Barrau (2015) suggest, the emergence of a certain circumstantial inconsistency in the turbulence of things. This perhaps better allows us both to understand and temper the force of the critique of world made by Morton. For Morton, our habits of thinking have become too fixed on a particular concept of world to the extent that we cannot see past this abstraction because we believe it to be the background for all other abstractions. The solution here, however, is not simply to get rid of world as a bad abstraction. As Alfred North Whitehead (1967) reminds us, it is possible, and indeed critical, to revisit and revise abstractions in order to make them do different kinds of work. So, rather than a term that leads us inevitably to an impasse between an expansionary impulse where world becomes everything, and a localizing one, the value of world might lie in its capacity to sensitize us to the circumstantial qualities of arrangements, variously forceful and felt, even while it acts as a reminder for us to remain attentive to how scenes of life are traversed and transformed by forces that cut transversally across scales, times, practices, and bodies (Stewart 2010). 
Third, thinking in terms of the circumstantial affirms the relational processuality of worlding as something that shapes possibilities for acting, sensing, and feeling. Different technologies of world-making fashion affective spacetimes through the active engineering of associations between arrays of proximate and distant things (Sloterdijk 2011; Thrift 2012) that generate, in turn, multiple senses of interiority and subjectivities. Methodologically, this means attending or becoming attuned to how worlds take shape, or, more accurately, to how the process of worlding takes shape, through circumstantial arrangements of bodies, machines and devices. It also involves, as Stewart also suggests, learning to produce accounts of the shapes of these worlds, perhaps through a scenographic/approach that plays deliberately with the ongoing process of backgrounding and foregrounding as a way to make worlds explicit without for a minute suggesting that they are mere aesthetic projections of human experience.

This, in turn, points to a fourth and final point about world: its ongoing value as a frame or scene of political and ethical engagement. To some extent of course, and as Joel Wainwright (2010) argues in relation to the work of Gramsci, engaging with worlds is inherently political insofar as it offers a critique of the limits and liabilities of this concept in relation to the very conditions of critique. It reminds us of what is at stake, ethically, when a singular world is invoked, and behooves us to recognize the temptations of transcendence that would elide the otherness of worlds beyond the self while holding onto a faith in their possible shareability (Harrison 2009; Irigaray 2008). But engaging with worlds might also be political and ethical insofar as it is about helping us to imagine and enact different arrangements of life. To do so is not to cede the ground to some kind of nostalgic humanism. It is, rather, to embrace the speculative dimensions of the concept of world in order, precisely, to foreground 
dimensions of thought, politics, or ecologies that often remain hidden from view

(Connolly 2011). In this sense, making the case for the existence of, or the coming into existence of post-phenomenological life worlds, is to remobilize the force of that concept as one that does not so much desensitize us to politics, but on the contrary, sensitizes us to how circumstances become conditions and constraints for thinking life otherwise.

\section{Notes}

${ }^{1}$ In the most recent edition of The Dictionary of Human Geography (2009) world appears many times as prefix but does not have an entry devoted to itself: it remains a supplementary prefix or suffix. More generally, unlike terms like place (see Cresswell 1996 2004; Casey 1993) or territory (see Elden, 2013), there are few books by geographers devoted to the critique, elaboration and analysis of world.

${ }^{2}$ Bryant offers a critique of different and by now familiar approaches to thinking about worlds, including Heidegger, who, Bryant suggests, merely gives an account of Dasein as a form of openness to world rather than an account of world itself. In this respect Bryant shares Morton's critique of phenomenological accounts of world as lived experience or horizon of meaning on the basis that these accounts elide the challenge of engaging with what world really is.

${ }^{3}$ See Summa Theologica, available at http://www.sacredtexts.com/chr/aquinas/summa/sum141.htm. Last accessed 12 February 2016.

${ }^{4}$ Crandall, Jordan. "Summary of Gatherings." Available at http://jordancrandall.com/main/+GATHERINGS/index.html. Last accessed November 122015. 


\section{References}

Adey P 2014 Security atmospheres or the crystallisation of worlds Environment and Planning D: Society and Space $32834-851$

Anderson B 2014 Encountering affect: apparatuses, capacities, conditions Farnham: Ashgate

Anderson B and McFarlane C 2011 Assemblage and geography Area 43 124-127

Anderson B and Wylie J 2009 On geography and materiality Environment and Planning, A 41 318-335

Anderson B and Harrison P eds 2010 Taking-place: nonrepresentational theory and geography Farnham: Ashgate

Ash J 2013 Rethinking affective atmospheres: technology, perturbation and space times of the non-human Geoforum 49 20-28

Ash J 2015 The interface envelope: gaming, technology, power London: Bloomsbury

Ash J and Simpson P 2016 Geography and post-phenomenology Progress in Human Geography 40 48-66

Bennett J 2010 Vibrant matter: a political ecology of things Durham, NC: Duke University Press

Bennington G 2000 Interrupting Derrida London: Routledge

Berlant L ed 2000 Intimacy Chicago: University of Chicago Press

Berlant L 2011 Cruel optimism Durham, NC: Duke University Press

Berlant L 2016 The commons: infrastructures for troubling times Environment and Planning D: Society and Space 34 393-419

Braudel F 1996 The Mediterranean and the Mediterranean world in the age of Philip II, volume 1 Chicago: University of Chicago Press 
Bryant L 2014 Onto-cartography: an ontology of machines and media Edinburgh: Edinburgh University Press.

Buchanan B 2008 Onto-ethologies: the animal environments of Uexküll, Heidegger, Merleau-Ponty, and Deleuze Albany NY: SUNY Press

Buttimer A 1976 Grasping the dynamism of the lifeworld Annals of the Association of American Geographers 68 277-292

Casey E 1993 Getting back into place: toward a renewed understanding of the placeworld Bloomington: Indiana University Press

Cheah P 2008 What is a world? On world literature as world-making activity Daedalus 137 26-38

Clark N 2006 The play of the world in Pryke M Rose G and Whatmore S eds Using Social theory: thinking through research London: Sage

Clough P, Gregory K, Haber B, and Scannell J 2014 The datalogical turn in Nonrepresentational methodologies: re-envisioning research ed P Vannini Oxford: Taylor \& Francis

Connolly W E 2011 A world of becoming Durham NC: Duke University Press Cresswell T 1996 In placelout of place: geography, ideology, transgression Minneapolis MN: University of Minnesota Press

Cresswell T 2004 Place: a short introduction Oxford: Blackwell

Cresswell T and Martin C 2012 On turbulence: tntanglements of disorder and order on a Devon beach Tijdschrift Voor Economische en Sociale Geographie 103 $516-529$

Deleuze G 1991 Empiricism and subjectivity: an essay on Hume's theory of human nature New York: Columbia University Press 
Deleuze G and Guattari F 1988 A thousand plateaus trans B Massumi London: Athlone Press

EIden S 2013 The birth of territory Chicago: University of Chicago Press

Entrikin JN 1976 Contemporary humanism in Geography Annals of the Association of American Geographers 66 615-632

Gaston S 2011 Derrida and the end of the world New Literary History 42 499-517

Gaston S 2013a Derrida and the eco-polemicists Paragraph 36 344-360

Gaston S 2013b The concept of world from Kant to Derrida London: Rowman Littlefield

Gibson-Graham JK 2008 Diverse economies: performative practices for other worlds Progress in Human Geography 32 613-632

Gregory D, Johnston R, Pratt G, Watts M, Whatmore S eds 2009 The cictionary of human geography, $5^{\text {th }}$ Ed Oxford: Wiley

Hansen M 2014 Feed-forward: On the future of twenty-first-century media Chicago: University of Chicago Press.

Harrison P 2007 Corporeal remains: vulnerability, proximity, and living on at the end of the world Environment and Planning A 40 423-445

Hartshorne R 1960 Perspective on the nature of geography London: John Murray Ingold T 2011 Being alive: essays on movement, knowledge and description London: Routledge

Ingold T 2010 Footprints through the weather-world: walking, breathing, knowing Journal of the Royal Anthropological Institute 16 121-139

Irigaray L 2008 Sharing the world London: Continuum

Irwin R 1985 Being and circumstance: notes towards a conditional art San Francisco: Lapis Press 
Kinsley S 2014 The matter of 'virtual' geographies Progress in Human Geography 38 364-384

Knox P and Taylor P eds 1996 World cities in a world system Cambridge:

Cambridge University Press

Latour B 2007 A plea for earthly sciences in J Burnett, S Jeffers and G Thomas eds New social connections: sociology's subjects and sbjects London: Palgrave Macmillan, 72-84

Lea J 2009 Post-phenomenology/post-phenomenological geographies in R Kitchin and N Thrift eds International Encyclopedia of Human Geography Oxford: Elsevier, 373-378

Leszczynski A 2015 Spatial media/tion Progress in Human Geography 39 729-751

Lorimer J 2012 Multinatural geographies for the snthropocene Progress in Human Geography 36 593-612

Marston S Jones J and Woodward K 2005 Human geography without scale Transactions of the Institute of British Geographers 30 416-432

Massey D 2005 For space London: Sage

McCormack D P 2013 Geography and abstraction: Towards an affirmative critique Progress in Human Geography 36 715-734

McCormack D P 2013 Refrains for moving bodies: experience and experiment in affective spaces Durham and London: Duke University Press

Marx K 2000 Selected writings ed D McClellan Oxford: Oxford University Press

Merriman P 2012 Human geography without time-space Transactions of the Institute of British Geographers 37 13-27

Morton T 2013 Hyperobjects: philosophy and ecology after the end of the world Minneapolis: University of Minnesota Press 
Morton T 2007 Ecology without nature: rethinking environmental aesthetics Cambridge, MA: Cambridge University Press

Muller M and Schurr C 2016 Assemblage thinking and actor-network theory: conjunctions, disjunctions, cross-fertilisations Transactions of the Institute of British Geographers 41 217-229

Nancy J-L 1997 The sense of the world tr S Jeffrey and S Librett Minneapolis: University of Minnesota Press

Nancy J-L and Barrau A 2015 What's these worlds coming to? tr T Holloway and F Méchain New York: Fordham University Press

Povinelli E 2011 Economies of abandonment: social belonging and endurance in late Liberalism Durham, NC: Duke University Press

Roberts T 2012 From 'new materialism' to 'machinic assemblages': agency and affect in IKEA Environment and Planning A 4410 2512-2529

Roelvink, St. Martin, K and Gibson-Graham, J-K eds 2015 Making other worlds possible: performing diverse economies Minneapolis: University of Minnesota Press

Rose G 1993 Feminism and geography: the limits to geographical knowledge Minneapolis: University of Minnesota Press

Rose M 2006 Gathering ‘dreams of presence': a project for the cultural landscape Environment and Planning D: Society and Space 24 537-554

Sabisch P 2011 Choreographing relations Munich: Epodium

Seamon D 1979 A geography of the lifeworld: movement, rest and encounter London: Routledge

Serres M 2008 The five senses: a philosophy of mingled bodies tr Margaret Sankey and Peter Cowley London: Athlone 
Shaw I 2010 Sites, truths and the logics of worlds: Alain Badiou and human geography Transactions of the Institute of British Geographers 35 431-442

Shaw I and Meehan M 2013 Force-full: power, politics, and object-oriented ontology Area 45 216-222

Simpson P 2009 'Falling on deaf ears': A post-phenomenology of sonorous presence Environment and Planning A 41 2556-2575.

Sloterdijk P 2011 Bubbles: spheres 1 tr W Hoban Cambridge MA: MIT Press

Stewart K 2015 New England red in P Vannini ed Nonrepresentational methodologies: re-envisioning research London: Routledge 19-33

Stewart K 2014 Road registers Cultural Geographies 21 549-563

Stewart K 2010 Afterword: worlding refrains in M Gregg and G Seigworth eds The Affect Theory Reader Durham NC: Duke University Press 339-354

Thrift N 2007 Non-representational theory: space, politics, affect London: Routledge

Thrift N 2011 Lifeworld Inc — and what to do about it Environment and Planning D: Society and Space $295-26$

Thrift N 2012 Peter Sloterdijk and the philosopher's stone in S Elden ed Sloterdijk Now Cambridge: Polity 133-146

Wainwright J 2010 On Gramsci's 'conceptions of the world' Transactions of the Institute of British Geographers 35 507-521

Wallerstein I 2012 World-systems analysis: an introduction Durham NC: Duke University Press

Whatmore S 2002 Hybrid geographies: natures, cultures, spaces London Sage Whitehead A N 1967 Science and the modern world New York: The Free Press Wylie J 2009 Landscape, absence and the geographies of love Transactions of the Institute of British Geographers 34 275-289 